\title{
Pemanfaatan Metode Kalman Filter Diskrit untuk Menduga Suhu Udara
}

\author{
Billy Arifa Tengger ${ }^{*}$, Ropiudin $^{2}$ \\ ${ }^{1}$ Universitas Nahdlatul Ulama Purwokerto, ${ }^{2}$ Universitas Jenderal Soedirman \\ *ba.tengger@unupurwokerto.ac.id
}

\begin{abstract}
ABSTRAK
Suhu adalah variabel fisik yang perlu diketahui secara tepat untuk penggunaan tertentu. Suhu adalah derajat panas dan dingin suatu benda. Derajat panas dan dingin ini dipengaruhi oleh enthalpi (energi) yang dimilki suatu zat. Pendugaan suhu udara dapat memberikan manfaat untuk aktivitas pada beberapa bidang, seperti: pertanian, peternakan, perikanan, kesehatan, dan kegiatankegiatan lainnya. Metode Kalman Filter Diskrit merupakan salah satu metode matematika yang dapat digunakan untuk menduga data di masa yang akan datang. Kalman Filter Diskrit memiliki keunggulan mampu menduga suatu kondisi berdasarkan data terbatas. Data pengukuran terbaru menjadi suatu bagian terpenting dalam algoritma Kalman Filter, karena data tersebut akan mengkoreksi data hasil pendugaan, sehingga hasil pendugaan selalu mendekati kondisi sesungguhnya. Berdasarkan hasil kajian yang telah dilakukan menggunakan metode Kalman Filter Diskrit untuk menduga suhu udara diperoleh ketepatan pendugaan nilai suhu udara di atas $95 \%$. Pedugaan dilakukan secara harian dan bulanan. Dengan demikian Kalman Filter Diskrit mampu dan handal untuk pendugaan suhu udara secara harian, bulanan, bahkan tahunan.
\end{abstract}

Kata Kunci: kalman filter diskrit, suhu, energi, pendugaan, ketepatan.

\begin{abstract}
Temperature is a physical variable that needs to be known precisely for certain uses. Temperature is the degree of heat and cold of an object. The degree of heat and cold is influenced by enthalpy (energy) which has a substance. Estimation of environmental temperature can provide benefits for activities in several fields, such as: agriculture, animal husbandry, fisheries, health, and other activities. The Discrete Kalman Filter method is one mathematical method that can be used to predict data in the future. The Discrete Kalman Filter have the advantage of being able to predict a condition based on limited data. The latest measurement data is the most important part of the Kalman Filter algorithm, because the data will correct the estimated data, so the estimation results are always close to the actual conditions. Based on the results of studies that have been carried out using The Discrete Kalman Filter method to estimate the temperature of the environment, the accuracy of the estimated value of the ambient temperature is above 95\%. Estimates are carried out on a daily and monthly basis. Thus The Discrete Kalman Filter is capable and reliable for estimating environmental temperature on a daily, monthly, or even annual basis.
\end{abstract}

Keywords: discrete kalman filter, temperature, energy, estimation, accuracy 


\section{PENDAHULUAN}

Suhu adalah variabel fisik yang perlu diketahui secara tepat untuk penggunaan tertentu. Suhu adalah derajat panas dan dingin suatu benda. Derajat panas dan dingin ini dipengaruhi oleh enthalpi (energi) yang dimilki suatu zat. Pendugaan suhu udara dapat memberikan manfaat untuk aktivitas pada beberapa bidang, seperti: pertanian, peternakan, perikanan, kesehatan, dan kegiatan-kegiatan lainnya. Pada penelitian terdahulu oleh Jesiani, E.M., dkk., telah dilakukan penelitian tentang pendugaan evaporasi dari suhu udara dan kelembaban udara menggunakan metode regresi linier berganda. Akan tetapi, metode regresi hanya dapat digunakan untuk minimal 2 variabel, yaitu variabel bebas dan variabel terikat. Jika hanya ada salah satu variabel, maka pendugaan variabel tidak dapat didekati dengan metode regresi. Oleh karena itu diperlukan suatu metode yang dapat menduga kondisi suhu udara hanya berdasarkan data sampel yang terbatas, namun dapat mewakili kondisi sesungguhnya. Salah satu metode yang dapat digunakan adalah metode Kalman Filter. Kalman Filter pertama kali dikenalkan oleh Rudolf E. Kalman pada Tahun 1960.

Kalman Filter adalah salah satu metode matematika yang dapat digunakan untuk menghitung estimator optimal suatu keadaan berdasarkan data yang tersedia. (Haykin, 2001). Selain itu, Kalman Filter juga merupakan salah satu metode runtun waktu yang dapat digunakan dalam menentukan ramalan ke depan. (Artanto \& Agoestanto, 2015:75-84) Menurut Vera Firmansyah (2018:1-7) menyatakan bahwa Kalman filter dapat memperkirakan keadaan suatu proses dengan cara meminimalkan kesalahan kuadrat rata-rata (mean square error) baik keadaan sebelumnya, saat ini dan yang akan datang. Keunggulan Kalman Filter adalah kemampuan mengestimasi / menduga suatu keadaan berdasarkan data yang terbatas. Data pengukuran terbaru menjadi suatu bagian terpenting dalam algoritma Kalman Filter, karena data tersebut akan mengkoreksi data hasil pendugaan, sehingga hasil pendugaan selalu mendekati kondisi sesungguhnya. Dalam estimasinya, Kalman Filter terdiri dari dua tahapan yaitu tahap prediksi dan tahap update. Berdasarkan model state-space, terdapat dua jenis Kalman Filter yaitu Kalman Filter linier dan Kalman Filter nonlinier. Pada Kalman Filter linier hanya terdapat satu metode yaitu Discrete Kalman Filter. Sedangkan pada Kalman Filter nonlinier terdapat dua metode, yaitu Extended Kalman Filter dan Unscented Kalman Filter (Haykin, 2001).

Berkaitan dengan pendugaan suhu udara berdasarkan data hasil pengukuran yang telah dilakukan secara berkala dan tanpa melibatkan faktor - faktor lain yang berpengaruh terhadap suhu udara, maka metode Discrete Kalman Filter (Kalman Filter Diskrit) merupakan pilihan yang tepat. Kalman Filter Diskrit merupakan metode Kalman Filter yang digunakan pada suatu sistem dengan waktu diskrit, artinya jarak antar waktu pengukuran konstan.

\section{METODE}

Data tentang suhu udara pada penelitian ini diambil dari website https://www. accuweather.com/id/id/banyumas/202874/weather-forecast/202874. Data tersebut merupakan data suhu udara di wilayah Banyumas yang diukur setiap hari, kemudian diambil nilai rata-

ratanya sehingga diperoleh data rata-rata suhu udara setiap bulan. Data rata-rata suhu udara yang digunakan adalah data rata-rata suhu udara pada bulan Juli 2018-Juli 2019. Metode yang 
digunakan dalam penelitian ini adalah metode Kalman Filter Diskrit, dikarenakan data yang diperoleh telah dilakukan secara berkala atau jarak antara waktu pengukuran konstan. Pada penelitian ini, hanya satu parameter saja yang kami uji menggunakan metode Kalman Filter Diskrit.

\section{HASIL DAN PEMBAHASAN}

Kalman Filter Diskrit merupakan metode Kalman Filter yang digunakan pada suatu sistem dengan waktu diskrit, artinya jarak antar waktu pengukuran konstan. Pada Kalman Filter Diskrit terdapat dua tahapan yaitu tahap prediksi dan tahap pembaruan (update). Tahap prediksi dilakukan dengan menggunakan perkiraan kondisi dari waktu sebelumnya untuk mendapatkan nilai dugaan pada saat ini. Tahap prediksi memiliki 2 perhitungan, yaitu: perhitungan pendugaan kondisi dan perhitungan galat kovarians. Sedangkan pada tahap update, informasi mengenai pengukuran pada saat ini digunakan untuk memperbaiki prediksi sehingga diharapkan pendugaan keadaan akan lebih akurat. Tahapan ini memiliki 3 perhitungan, yakni: perhitungan Kalman gain, update pendugaan kondisi, dan update galat kovarians. Secara umum, algoritma untuk metode Kalman Filter Diskrit dituliskan dalam bentuk berikut.

Tahap Prediksi

Tahap Update

$$
\begin{gathered}
\widehat{\boldsymbol{x}}_{k}^{-}=\boldsymbol{F}_{k, k-1} \widehat{\boldsymbol{x}}_{k-1} ; \\
\boldsymbol{P}_{k}^{-}=\boldsymbol{F}_{k, k-1} \boldsymbol{P}_{k-1} \boldsymbol{F}_{k, k-1}^{T}+\boldsymbol{Q}_{k-1} ;
\end{gathered}
$$

$$
\begin{gathered}
\boldsymbol{G}_{k}=\boldsymbol{P}_{k}^{-} \boldsymbol{H}_{k}^{T}\left[\boldsymbol{H}_{k} \boldsymbol{P}_{k}^{-} \boldsymbol{H}_{k}^{T}+\boldsymbol{R}_{k}\right]^{-\mathbf{1}} ; \\
\widehat{\boldsymbol{x}}_{k}=\widehat{\boldsymbol{x}}_{k}^{-}+\boldsymbol{G}_{k}\left(\boldsymbol{y}_{k}-\boldsymbol{H}_{k} \widehat{\boldsymbol{x}}_{k}^{-}\right) ; \\
\boldsymbol{P}_{k}=\left(\boldsymbol{I}-\boldsymbol{G}_{k} \boldsymbol{H}_{k}\right) \boldsymbol{P}_{k}^{-}
\end{gathered}
$$

Penelitian ini hanya menduga 1 parameter yang akan dilakukan pendugaan menggunakan Kalman Filter Diskrit yaitu suhu, sehingga persamaan-persamaan pada algorima Kalman Filter Diskrit dapat direduksi menjadi skalar dengan asumsi bahwa $\boldsymbol{F}_{k, k-1}=\boldsymbol{H}_{k}=1$. Pada model ini, data pengukuran rata-rata suhu udara setiap bulan direpresentasikan dengan $y_{k}$. Oleh karena itu, algoritma dalam melakukan pendugaan suhu udara menggunakan metode Kalman Filter Diskrit adalah sebagai berikut.

a. Diketahui : data pengukuran suhu udara $\left(y_{k}\right)$.

b. Ditanyakan : $\hat{x}_{k}^{-}, P_{k}^{-}, G_{k}, \hat{x}_{k}, P_{k}$ dengan $k=1,2, \ldots, n$

c. Langkah-langkah :

1. Menentukan nilai awal $\hat{x}_{0}$ dan $P_{0}$.

2. Untuk $k=1,2, \ldots, n$, hitung :

$>$ Tahap Prediksi

$$
\begin{gathered}
\hat{x}_{k}^{-}=\hat{x}_{k-1} ; \\
P_{k}^{-}=P_{k-1}+Q_{k-1} ;
\end{gathered}
$$

Tahap Update

$$
\begin{gathered}
G_{k}=P_{k}^{-}\left[P_{k}^{-}+R_{k}\right]^{-1} ; \\
\hat{x}_{k}=\hat{x}_{k}^{-}+G_{k}\left(y_{k}-\hat{x}_{k}^{-}\right) ; \\
P_{k}=\left(I-G_{k}\right) P_{k}^{-}
\end{gathered}
$$


Suhu adalah variabel fisik yang perlu diketahui secara tepat untuk penggunaan tertentu. Suhu adalah derajat panas dan dingin suatu benda. Derajat panas dan dingin ini dipengaruhi oleh enthalpi (energi) yang dimilki suatu zat. Pendugaan suhu udara dapat memberikan manfaat untuk aktivitas pada beberapa bidang, seperti: pertanian, peternakan, perikanan, kesehatan, dan kegiatan-kegiatan lainnya. Pengukuran suhu dapat dilakukan menggunakan termometer ruang. Rekapitulasi data pengukuran rata-rata suhu udara dari bulan Juli 2018 hingga Juli 2019 disajikan dalam Tabel 1.

Tabel 1. Rata-Rata Suhu udara di Wilayah Banyumas

\begin{tabular}{lc}
\hline \multicolumn{1}{c}{ Bulan } & Rata-Rata Suhu $\left({ }^{\circ} \mathbf{C}\right)$ \\
\hline Juli 2018 & 25,77 \\
Agustus 2018 & 25,66 \\
September 2018 & 26,85 \\
Oktober 2018 & 27,61 \\
November 2018 & 27,4 \\
Desember 2018 & 27,6 \\
Januari 2019 & 28,45 \\
Februari 2019 & 28,3 \\
Maret 2019 & 27,84 \\
April 2019 & 28,78 \\
Mei 2019 & 28,27 \\
Juni 2019 & 26,05 \\
Juli 2019 & 25,52 \\
\hline
\end{tabular}

Sumber : https://www.accuweather.com/id/id/banyumas/202874/weather-forecast/202874

Berdasarkan data pengukuran yang diperoleh, akan dilakukan pendugaan rata-rata suhu udara pada pengukuran bulan selanjutnya. Selanjutnya berdasarkan algoritma Kalman Filter Diskrit dipilih nilai awal $\hat{x}_{0}=25$ dan $P_{0}=0,05$. Kemudian dengan menggunakan bantuan software Microsoft Excel 2011 dan Matlab R2017a diperoleh perhitungan pendugaan, dan plot grafik sebagai berikut.

Tabel 2. Hasil Perhitungan Pendugaan Suhu udara Menggunakan Metode Kalman Filter Diskrit

\begin{tabular}{|c|c|c|c|c|c|c|c|c|}
\hline \multirow[b]{2}{*}{ Bulan } & \multicolumn{2}{|c|}{$\begin{array}{c}\text { Tahap } \\
\text { Prediksi }\end{array}$} & \multirow{2}{*}{$\begin{array}{c}\text { Hasil } \\
\text { Pengukuran } \\
y_{k}\end{array}$} & \multicolumn{3}{|c|}{ Tahap Update } & \multicolumn{2}{|c|}{ Galat (\%) } \\
\hline & $\hat{x}_{k}^{-}$ & $P_{k}^{-}$ & & $G_{k}$ & $\hat{x}_{k}$ & $P_{k}$ & $\begin{array}{c}\text { Absolut } \\
\text { Galat } \\
\text { Prior }\end{array}$ & $\begin{array}{c}\text { Absolut } \\
\text { Galat } \\
\text { Posterior }\end{array}$ \\
\hline Juli 2018 & 25 & 0,11 & 25,77 & 0,89 & 25,69 & 0,01 & $2,99 \%$ & $2,67 \%$ \\
\hline Agustus 2018 & 25,69 & 0,05 & 25,66 & 0,82 & 25,66 & 0,01 & $0,11 \%$ & $0,09 \%$ \\
\hline September 2018 & 25,66 & 0,05 & 26,85 & 0,43 & 26,18 & 0,03 & $4,41 \%$ & $1,90 \%$ \\
\hline Oktober 2018 & 26,18 & 0,05 & 27,61 & 0,36 & 26,69 & 0,03 & $5,20 \%$ & $1,86 \%$ \\
\hline November 2018 & 26,69 & 0,08 & 27,4 & 0,74 & 27,21 & 0,02 & $2,60 \%$ & $1,92 \%$ \\
\hline Desember 2018 & 27,21 & 0,06 & 27,6 & 0,4 & 27,37 & 0,03 & $1,40 \%$ & $0,55 \%$ \\
\hline Januari 2019 & 27,37 & 0,1 & 28,45 & 0,88 & 28,32 & 0,01 & $3,81 \%$ & $3,37 \%$ \\
\hline
\end{tabular}




\begin{tabular}{|c|c|c|c|c|c|c|c|c|}
\hline \multirow[b]{2}{*}{ Bulan } & \multicolumn{2}{|c|}{$\begin{array}{c}\text { Tahap } \\
\text { Prediksi }\end{array}$} & \multirow{2}{*}{$\begin{array}{c}\text { Hasil } \\
\text { Pengukuran } \\
y_{k}\end{array}$} & \multicolumn{3}{|c|}{ Tahap Update } & \multicolumn{2}{|c|}{ Galat (\%) } \\
\hline & $\hat{x}_{k}^{-}$ & $P_{k}^{-}$ & & $G_{k}$ & $\hat{x}_{k}$ & $P_{k}$ & $\begin{array}{c}\text { Absolut } \\
\text { Galat } \\
\text { Prior }\end{array}$ & $\begin{array}{l}\text { Absolut } \\
\text { Galat } \\
\text { Posterior }\end{array}$ \\
\hline Februari 2019 & 28,32 & 0,03 & 28,3 & 0,33 & 28,32 & 0,02 & $0,09 \%$ & $0,03 \%$ \\
\hline Maret 2019 & 28,32 & 0,1 & 27,84 & 0,83 & 27,92 & 0,02 & $1,71 \%$ & $1,42 \%$ \\
\hline April 2019 & 27,92 & 0,07 & 28,78 & 0,87 & 28,67 & 0,01 & $2,98 \%$ & $2,60 \%$ \\
\hline Mei 2019 & 28,67 & 0,04 & 28,27 & 0,5 & 28,47 & 0,02 & $1,41 \%$ & $0,71 \%$ \\
\hline Juni 2019 & 28,47 & 0,05 & 26,05 & 0,99 & 26,07 & 0,00 & $9,29 \%$ & $9,22 \%$ \\
\hline Juli 2019 & 26,07 & 0,07 & 25,52 & 0,7 & 25,68 & 0,02 & $2,15 \%$ & $1,50 \%$ \\
\hline
\end{tabular}

Berikut adalah gambar grafik yang diperoleh berdasarkan perhitungan pada Tabel 2 .

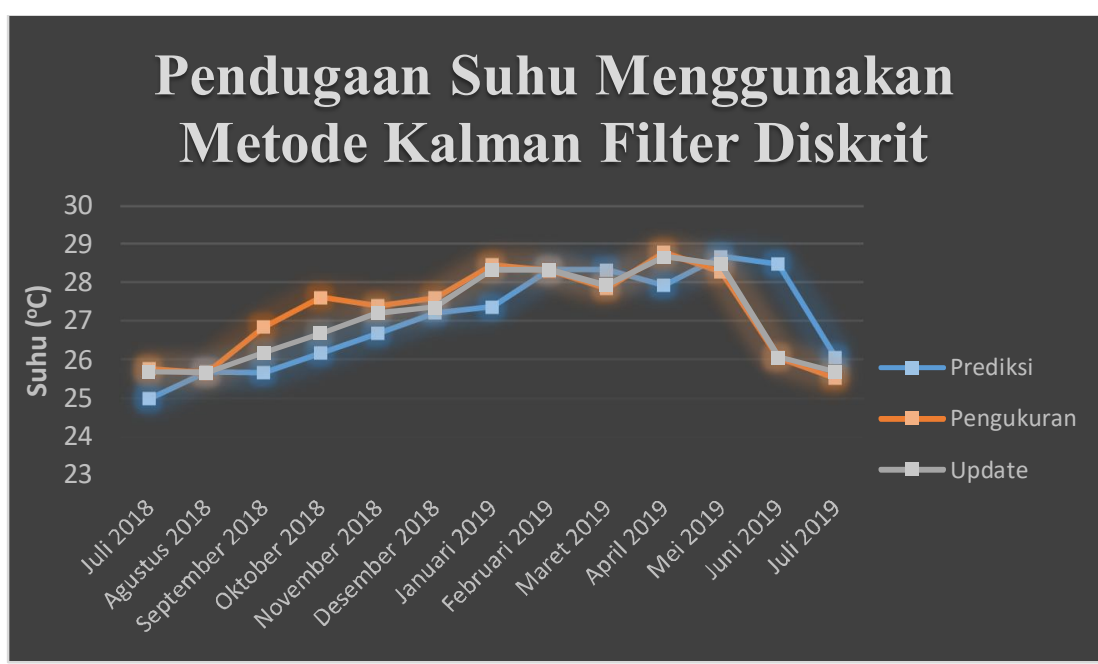

Gambar 1. Pendugaan Suhu Menggunakan Metode Kalman Filter Diskrit

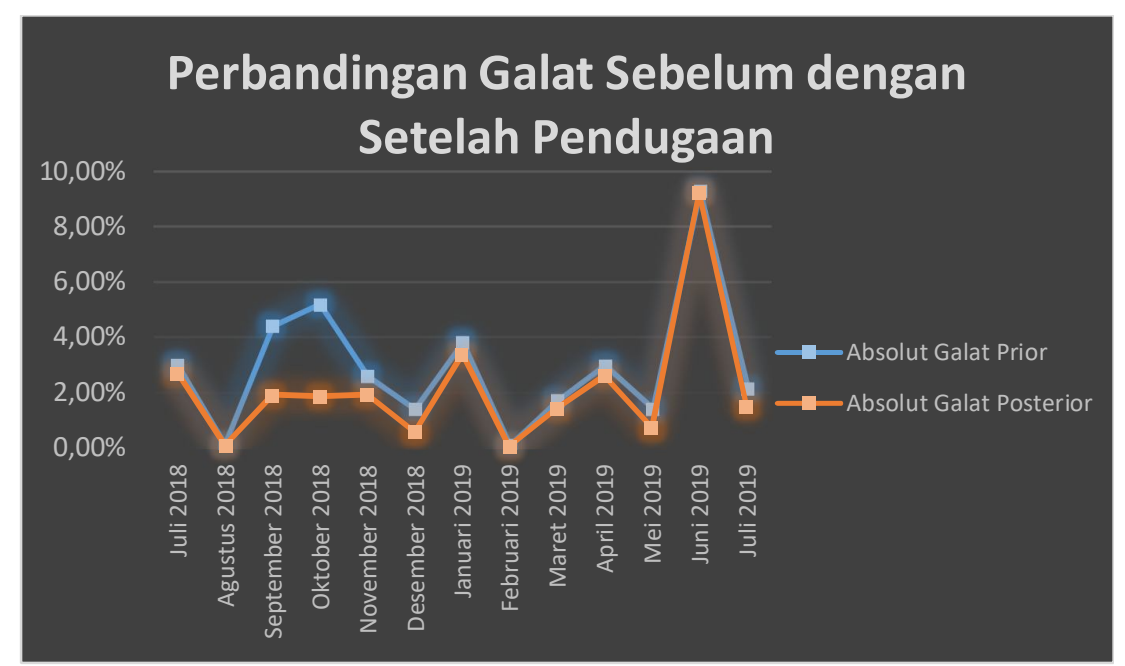

Gambar 2 : Perbandingan Galat Sebelum dengan Setelah Pendugaan 
Pada Gambar 1, terlihat bahwa metode Kalman Filter Diskrit membuat pendugaan suhu udara mendekati hasil pengukuran sesungguhnya. Pada pendugaan ini, diperoleh nilai 25,68 ${ }^{\circ} \mathrm{C}$ sebagai prediksi data rata-rata suhu udara pada pengukuran bulan selanjutnya di Wilayah Banyumas. Pada Gambar 2, terlihat bahwa galat yang terjadi sebelum dan setelah pendugaan menggukanan metode Kalman Filter Diskrit berangsur-angsur menurun hingga berada di bawah 5\%. Jadi metode ini memiliki ketepatan pendugaan yang sangat akurat dalam menduga suhu udara.

\section{SIMPULAN}

Kalman Filter Diskrit merupakan metode Kalman Filter yang digunakan pada suatu sistem dengan waktu diskrit, artinya jarak antar waktu pengukuran konstan. Pada Kalman Filter Diskrit terdapat dua tahapan yaitu tahap prediksi dan tahap pembaruan (update). Pada pendugaan ini, diperoleh nilai $25,68{ }^{\circ} \mathrm{C}$ sebagai prediksi data rata-rata suhu udara pada pengukuran bulan selanjutnya di Wilayah Banyumas. Galat yang terjadi sebelum dan setelah pendugaan pada penelitian ini berangsur-angsur menurun hingga berada di bawah 5\%. Sehingga metode ini memiliki ketepatan pendugaan yang sangat akurat dalam menduga suhu udara. Pada penelitian ini, hanya satu parameter yang diestimasi menggunakan discrete Kalman filter sehingga persamaan-persamaan pada setiap tahap estimasi direduksi menjadi skalar. Pembaca yang berminat dapat menggunakan metode Kalman Filter Diskrit ini untuk mengestimasi data dengan beberapa parameter, atau mencoba metode Kalman Filter lain seperti Extended Kalman Filter atau Unscented Kalman Filter.

\section{DAFTAR PUSTAKA}

Anonim. (2019). Kondisi Cuaca Banyumas. https://www.accuweather.com /id/id/banyumas/202874/weather-forecast/202874. Diakses pada 9 Agustus 2019.

Artanto, N., \& Agoestanto, A. (2015). Perbandingan Peramalan Curah Hujan Dengan Metode Bayesian Model Averaging dan Kalman Filter. UNNES Journal of Mathematics, 4(1), 75-84.

Bishop, G., \& Welch, G. (2006). An Introduction to the Kalman Filter. Proc. Siggraph Course. 8, 1-16.

Firmansyah, V. (2018). Aplikasi Kalman Filter pada Pembacaan Sensor Suhu untuk Pemantauan Kondisi Ruangan Laboratorium. Jurnal Materian dan Energi Indonesia, $8(1), 1-7$.

Harvey, A. C. (2003). Forecasting Structural Time Series Models and The Kalman Filter. Cambridge University Press. Cambridge.

Haykin, S. (2001). Kalman Filtering and Neural Networks. John Wiley \& Sons, Inc. New York.

Jesiani, E.M., Apriansyah \& Adriat, R. (2019). Model Pendugaan Evaporasi dari Suhu Udara dan Kelembaban Udara Menggunakan Metode Regresi Linier Berganda di Kota Pontianak. Jurnal : Prisma Fisika, 7(1), 46-50.

Kalman, R.E., (1960). A New Approach to Linear Filtering and Prediction Problem. Transactions of the ASME-Journal of Basic Engineering. 82(1), 34-45. 